\title{
Pagsusuri sa kahusayan at kabisaan ng likhang- modyul
}

Oclinaria, Avelina

Visayas State University, Philippines (Aoclinaria92@gmail.com)

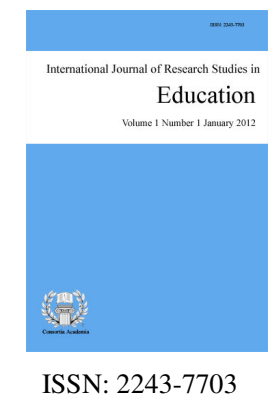

\section{Abstract}

Hinahangad sa pag-aaral na ito na masuri ang kaangkupang pangnilalaman sa nilikhang modyul na nagtataglay ng gabay para sa estudyante at guro na may katiyakang magbibigay ng karagdagang pagkatuto. Ang likhang-modyul na tinataya ay isa sa asignaturang Filipino para sa Baitang 11. Kakikitaan ito ng anim na bahagi: Paksa, Tiyak na Layunin, Pangganyak, Talakayan, Malikhaing Gawain at Ebalwasyon. Nakapaloob dito ang mga aralin tungkol sa linggwistika at pananaliksik na naaayon sa balangkas ng ika-21 siglong kasanayan para sa makabagong mag-aaral. Mahalaga ang pag-aaral na ito sa mga mananaliksik upang magkaroon ng saligan para sa mas malawak pang pag-aaral sa pagbuo ng mabisang modyul na magagamit sa pagtuturo ng Filipino na naaangkop sa kasalukuyang kalakaran ng edukasyon sa bansa. Ang kaangkupang pangnilalaman ay tinataya ng mga estudyante batay sa kaalamang linggwistika, kaalamang pananaliksik, gawain at ebalwasyon. Ginagamit ang talatanungan sa pagtataya sa kaangkupang pangnilalaman ng likhang-modyul na nagpapakita ng mga bahaging sinusuri batay sa angkop na katangian ng isang mahusay na kagamitang pampagtuturo. Ginamit ang assessment scale upang matugunan ang kaangkupang pangnilalaman ng likhang-modyul. Batay sa kinalalabasan ng pagtataya ng mga estudyante napatutunayan na ang kaangkupang pangnilalaman ng likhang-modyul ay angkop na angkop. Sa naging resulta ng pidbak ng mga estudyante, naipakita ng likhang-modyul ang kalinawan, kawastuan, kaangkupan at kawilihan sa nilalaman at kasanayang dapat matututunan ng mga estudyante. Napansin din ang mga kinakailangan ng modyul para sa kahusayan nito tungo sa pagpapayaman ng likhang-modyul.

Keywords: likhang-modyul; kaangkupang pangnilalaman; kawilihan; kabisaan; kahusayan 


\section{Pagsusuri sa kahusayan at kabisaan ng likhang- modyul}

\section{Introduksyon}

Sa programang K-12, layunin ng pagtuturo na malinang ang kakayahang komunikatibo, replektibo o mapanuring pag-iisip at pagpapahalagang pampanitikan ng mga mag-aaral sa pamamagitan ng mga babasahin at teknolohiya tungo sa pagkakaroon ng pambansang pagkakakilanlan, kultural na literasi at patuloy na pagkatuto upang makaagapay sa mabilis na pagbabagong naganap sa daigdig (Luistro,2012). Sa ikatatamo ng mithiing ito, kailangan ng mga pantulong ng mga guro maliban sa mga kagamitang pampagtuturo, kailangan ang angkop na mga estratehiya. Hinahangad sa pag-aaral na ito na masuri ang kaangkupang pangnilalaman sa nilikhang modyul na nagtataglay ng gabay para sa estudyante at guro na may katiyakang magbibigay ng karagdagang pagkatuto. Ang likhang-modyul na tinataya ay isa sa asignaturang Filipino para sa Baitang 11. Kakikitaan ito ng anim na bahagi: Paksa, Tiyak na Layunin, Pangganyak, Talakayan, Malikhaing Gawain at Ebalwasyon. Nakapaloob dito ang mga aralin tungkol sa linggwistika at pananaliksik na naaayon sa balangkas ng ika-21 siglong kasanayan para sa makabagong mag-aaral. Mahalaga ang pag-aaral na ito sa mga mananaliksik upang magkaroon ng saligan para sa mas malawak pang pag-aaral sa pagbuo ng mabisang modyul na magagamit sa pagtuturo ng Filipino na naaangkop sa kasalukuyang kalakaran ng edukasyon sa bansa.

Ang kaangkupang pangnilalaman ay tinataya ng mga estudyante batay sa kaalamang linggwistika, kaalamang pananaliksik, gawain at ebalwasyon. Ginagamit ang talatanungan sa pagtataya sa kaangkupang pangnilalaman ng likhang-modyul na nagpapakita ng mga bahaging sinusuri batay sa angkop na katangian ng isang mahusay na kagamitang pampagtuturo. Ginamit ang assessment scale upang matugunan ang kaangkupang pangnilalaman ng likhang-modyul. Batay sa kinalalabasan ng pagtataya ng mga estudyante napatutunayan na ang kaangkupang pangnilalaman ng likhang-modyul ay angkop na angkop.

Sa naging resulta ng pidbak ng mga estudyante, naipakita ng likhang-modyul ang kalinawan, kawastuan, kaangkupan at kawilihan sa nilalaman at kasanayang dapat matututunan ng mga estudyante. Napansin din ang mga kinakailangan ng modyul para sa kahusayan nito tungo sa pagpapayaman ng likhang-modyul. Dahil sa kaliwa- kanang pagtuligsa at puna sa mga kagamitang panturo para sa $\mathrm{K}$ to12, partikular na ang mga modyul na ipinamahagi mga pribado at pampublikong paaralan ay dumaan sa masusing pagtataya ang mga ito. Tinitiyak na tumatahak sa ika-21siglong kasanayan ang modyul na nabanggit upang maiaayon sa ika-21 siglong mag-aaral.

"With the lack of qualified teachers, lack of resources, then extending the cycle might compound the problem.” (Bernido, 2012), Nakita niya ang kakulangan sa kagamitang maaaring magamit ng mga guro sa pagtuturo. Bagong pasanin ito na kailangang gampanan ng mga guro.

Taon 2012, nagsimula nang ipinatupad ang programang K to12 sa buong kapuluan ng Pilipinas. Walang papasok sa unang antas ng kolehiyo sa Academic Year 2016-2017. Ang implikasyon nito ay ang mga nagtuturo ng Filipino sa kolehiyo ay walang matuturuan. Para matugunan ang pangangailangan at serbisyo ng mga guro sa Visayas State University ay pinaturo ang mga guro sa nasabing paaralan sa Senior High School. Malaking problema sa mga guro roon ang pagtuturo, dahil walang batayan o kagamitang pampagtuturo para sa pagkatuto ng mga mag-aaral.

Ipinaubaya ng administrasyon sa mga guro ang istratehiya at mga inobasyon ng kagamitang pagtuturo. Sa ganitong sitwasyon napansin ng mananaliksik na ang bawat guro na nagtuturo sa nasabing asignatura ay gumamit ng kahit anong batayan sa pagtuturo dahil sa kakulangan ng materyal kung kaya hindi na angkop. Ito ang nakitang suliranin ng mananaliksik. Kaya bumuo ang mananaliksik ng modyul sa asignaturang KPWKP101 (Komunikasyon at Pananaliksik sa Wika at Panitikang Pilipino) para sa Baitang 11 tungo sa pagkatutong panglinggwistika. 
Ang pag-aaral ay nakakawing sa konsepto ni Tomlinson (1998) na kinakailangang mataya ang isang kagamitang pagtuturo sa komunikatibong aspekto nito (communicative methodology) dahil nakabatay ito sa pagiging awtentiko, makatotohanan, at nakatuon sa mga mag-aaral. Sa konsepto nina Richards at Rodgers (2001), makilala ang mga gawain na pinatnubayan ng komunikatibong pagdulog sa pamamagitan ng pagsisikap na mailahad ang makahulugan at makatotohanan na pakikipagtalastasan sa lahat ng antas. Bilang resulta, maaaring may higit pang pagbibigay-diin sa kasanayan kaysa pamaraan o sistema; ang mga aralin ay nakatuon sa mag-aaral; at maaaring gumagamit ng awtentikong kagamitan. Napatunayan ni Kitao (1997) na ang komunikatibong pamamaraan ay may payak na hangarin: paghanap ng impormasyon, paghawan ng balakid, pagsasalita tungkol sa sarili at pagkatuto tungkol sa kultura.

\subsection{Layunin ng pag-aaral}

Ang pangunahing layunin sa pag-aaral ay mataya ang kahusayan at kabisaan ng likhang-modyul para sa Baitang 11. Tiniyak na sagutin ang sumusunod: (1) ang kaangkupang pangnilalaman batay sa 1.1 kaalamang linggwistika; 1.2 kaalamang pananaliksik; 1.3 gawain; at 1.4 ebalwasyon. (2) pidbak ng mga estudyante gamit ang modyul.

\section{Metodolohiya at pamamaraan}

\subsection{Disenyo ng pag-aaral}

Ang pag-aaral na ito ay gumamit ng pamaraang Deskriptib-Analitikal. Inilarawan ng mananaliksik ang mga tugon at pagsusuri ng mga estudyante sa likhang-modyul, maging ang resulta sa isinagawang pagsusuri ng likhang-modyul na kinasangkutan ng mga mag-aaral. Ang paglalarawang isinagawa ng mananaliksik ay ukol sa mga datos na nakalap kaugnay ekspertong ng resulta ng pagsusuri ng mga estudyante. Inaanalisa ng mananaliksik ang resulta ng pagtataya sa kaangkupang pangnilalaman at ang pagsusuri sa kabisaan ng mga bahagi ng likhang-modyul. Ganundin ang pidbak ng mga estudyante gamit ang likhang-modyul.

\subsection{Pamamaraan sa paglikom ng datos}

Ginamit ang talatanungan bilang instrumento sa pagtataya at pagsusuri ng likhang-modyul. Isinagawa at dinisenyo ng mananaliksik ang talatanungan batay sa modelo sa pagsagawa ng ebalwasyon para sa kagamitang pagtuturo na tumutugon sa ika-12 siglong kasanayan hango sa Framework ng Associaton and Partnership ng 21 st - Century Skills ni Zamora (2016) at binigyan ito ng rebisyon. Ipinamigay ang likhang-modyul sa nabanggit na mga respondenteng estudyante. Binigyan ng takdang panahon ang mga estudyante sa pagbabasa at pagsasagot sa mga inihandang gawain at ebalwasyon ng modyul. Bawat modyul ay binigyan din ng pasulat na pidbak mula sa mga estudyante.

Gamit ang talatanungan sinuri ng mga mag-aaral ang kaangkupang pangnilalaman ng modyul batay sa 1) kaalamang linggwistika, 2) kaalamang pananaliksik, 3) malikhaing gawain at 4) ebalwasyon. Gagamitin ang iskalang Likert sa pagmamarka tulad ng sumusunod: 5-Lubos na sumasang-ayon, 4- Sumasang-ayon, 3-Hindi tiyak, 2-Hindi sumasang-ayon, 1-Lubos na hindi sumasang-ayon. Hinanay ang mga resulta ng pagsusuri sa likhang modyul at pagkatapos ay idinaan ito sa istatistikal na pagtataya. Ang pidbak ng mga estudyante ang binabatayan ng mananaliksik sa pagrebisa ng likhang-modyul tungo sa kahusayan at pagyaman nito.

Upang masagot ang kaangkupan at kabisaan ng likhang-modyul ginamit ang istatistikal na pagsusuri na weighted mean. Formula: $\mathrm{Xw}=\Sigma f \mathrm{x}$ where: $\mathrm{Xw}=$ weighted mean

$$
\mathrm{X}=\text { assigned weights (5-LS, 4-S, 3-DT, 2-DS, 1-LDS) } \mathrm{f}=\text { frequency / number of respondents }
$$




\section{Resulta at talakayan}

\subsection{Kaangkupang Pangnilalaman ng Likhang-Modyul}

Ang Talahanayan 1 ay nagpapakita ng kinalalabasan ng pagtataya ng mga estudyante sa kaangkupang pangnilalaman ng likhang-modyul. Nasagot dito ang kaangkupang pangnilalaman ng modyul batay sa kaalamang linggwistika, kaalamang pananaliksik, gawain at ebalwasyon. Ang mananaliksik ay gumamit ng assessment scale upang matugunan ang kaangkupang pangnilalaman ng likhang-modyul.

Ito ang kinalalabasan ng nasasabing pagtataya ng mga estudyante sa likhang-modyul.

\section{Talahanayan 1}

Kaangkupang pangnilalaman

\begin{tabular}{|c|c|c|c|}
\hline Nilalaman & $\begin{array}{l}\text { Kadalasan } \\
\text { (Frequency) }\end{array}$ & $\begin{array}{c}\text { Average Weighted } \\
\text { Mean }\end{array}$ & Diskripsyon/Interpretasyon \\
\hline 1.1 Kaalamang Linggwistika & 80 & 4.87 & Angkop na angkop \\
\hline 1.2 Kaalamang Pananaliksik & 80 & 4.77 & Angkop na angkop \\
\hline 1.3 Malikhaing Gawain & 80 & 4.69 & Angkop na angkop \\
\hline 1.4 Ebalwasyon & 80 & 4.66 & Angkop na angkop \\
\hline
\end{tabular}

Modyul 2. Phatic, Emotive, at Expressive na Gamit ng Wika; Mga Katangian ng Mabuting Pananaliksik at ang mga Uri Nito

\begin{tabular}{lccc}
\hline \multicolumn{1}{c}{ Nilalaman } & $\begin{array}{c}\text { Kadalasan } \\
\text { (Frequency) }\end{array}$ & $\begin{array}{c}\text { Average } \\
\text { Mean }\end{array}$ & Deighted \\
\hline 2.1 Kaalamang Linggwistika & 80 & 4.67 & Angkop na angkop \\
2.2 Kaalamang Pananaliksik & 80 & 4.62 & Angkop na angkop \\
2.3 Malikhaing Gawain & 80 & 4.51 & Angkop na angkop \\
2.4 Ebalwasyon & 80 & 4.49 & Angkop na angkop \\
\hline
\end{tabular}

Modyul 3. Instrumental, Regulatori at Heuristikong Tungkulin ng Wika; Mga Pananagutan at Katangiang Dapat Taglayin ng Isang Mananaliksik

\begin{tabular}{|c|c|c|c|}
\hline Nilalaman & $\begin{array}{c}\text { Kadalasan } \\
\text { (Frequency) }\end{array}$ & $\begin{array}{c}\text { Average Weighted } \\
\text { Mean }\end{array}$ & Diskripsyon/Interpretasyon \\
\hline 3.1 Kaalamang Linggwistika & 80 & 4.38 & Angkop na angkop \\
\hline 3.2 Kaalamang Pananaliksik & 80 & 4.33 & Angkop na angkop \\
\hline 3.3 Malikhaing Gawain & 80 & 4.28 & Angkop na angkop \\
\hline 3.4 Ebalwasyon & 80 & 4.58 & Angkop na angkop \\
\hline \multicolumn{4}{|c|}{ Modyul 4.Interaksyunal, Personal at Imahinatibong Tungkulin ng Wika; Ang Isyu ng Plagyarismo } \\
\hline Nilalaman & $\begin{array}{l}\text { Kadalasan } \\
\text { (Frequency }\end{array}$ & $\begin{array}{c}\text { Average Weighted } \\
\text { Mean }\end{array}$ & Diskripsyon/Interpretasyon \\
\hline 4.1 Kaalamang Linggwistika & 80 & 4.65 & Angkop na angkop \\
\hline 4.2 Kaalamang Pananaliksik & 80 & 4.69 & Angkop na angkop \\
\hline 4.3 Malikhaing Gawain & 80 & 4.63 & Angkop na angkop \\
\hline 4.4 Ebalwasyon & 80 & 4.67 & Angkop na angkop \\
\hline
\end{tabular}

Mapapansin sa talahanayan na ang modyul 1 at modyul 2 ay parehong kaalamang linggwistika ang nagtamo ng pinakamataas na average weighted mean. Sa modyul 3 ang ebalwasyon ay nagtamo ng pinakamataas na average weighted mean at sa modyul 4 ang kaalamang pananaliksik ay nagtamo ng pinakamataas na average wighted mean. Ito ay nangangahulugan na ang kaalamang linggwistika ng likhang-modyul ay may lohikal na pagkasunud-sunod ng mga detalye. Payak, malinaw at nauunawaan. Ang mga ideya nito ay malinaw na nagpapakita kung paano nagkaugnay-ugnay ang mga ideya. Ang bahaging ebalwasyon ay nagpapakita ng ganap na pag-unawa ng estudyante sa paksa. Ang mga katanungan nito ay akma sa paksang-aralin. Ang mga aytem ay nakahanay sa layunin ng aralin at natitiyak ng estudyante ang gusto nilang maabot na kaalaman. Ang paglalahad 
Pagsusuri sa kahusayan at kabisaan ng likhang- modyul

sa kaalamang pananaliksik ay epektibong nagpanatili sa interes ng mga estudyante at may kaugnayan sakultura at literasi lebel. Bagama't magkaiba ang mga natamong average weighted mean, sa kabuoan makikita sa talahanayan na angkop na angkop ang bawat nilalaman sa apat na modyul. Ito ay nagpapatunay na ang mga estudyante ay lubos na sumasang-ayon sa mga katangian ng bawat bahagi ng likhang-modyul. Sa kabuuan ito ay nangangahulugan na ang kaangkupang pangnilalaman ng likhang-modyul ay angkop na angkop.

\subsection{Pidbak ng mga Estudyante Gamit ang Modyul}

Ipinapakita sa Talahanayan 2 ang pidbak ng mga estudyante gamit ang likhang-modyul para sa pagpapayaman nito. Makikita sa talahanayan ang mga nakasulat na pidbak ng mga estudyante mula sa modyul 1 , modyul 2, modyul 3 at modyul 4 na ginagamit ng mananaliksik sa pagbalangkas at pag-uri-uri ng mga pahayag para sa pagbuo ng makabuluhang tema.

\section{Talahanayan 2}

Pidbak ng mga estudyante

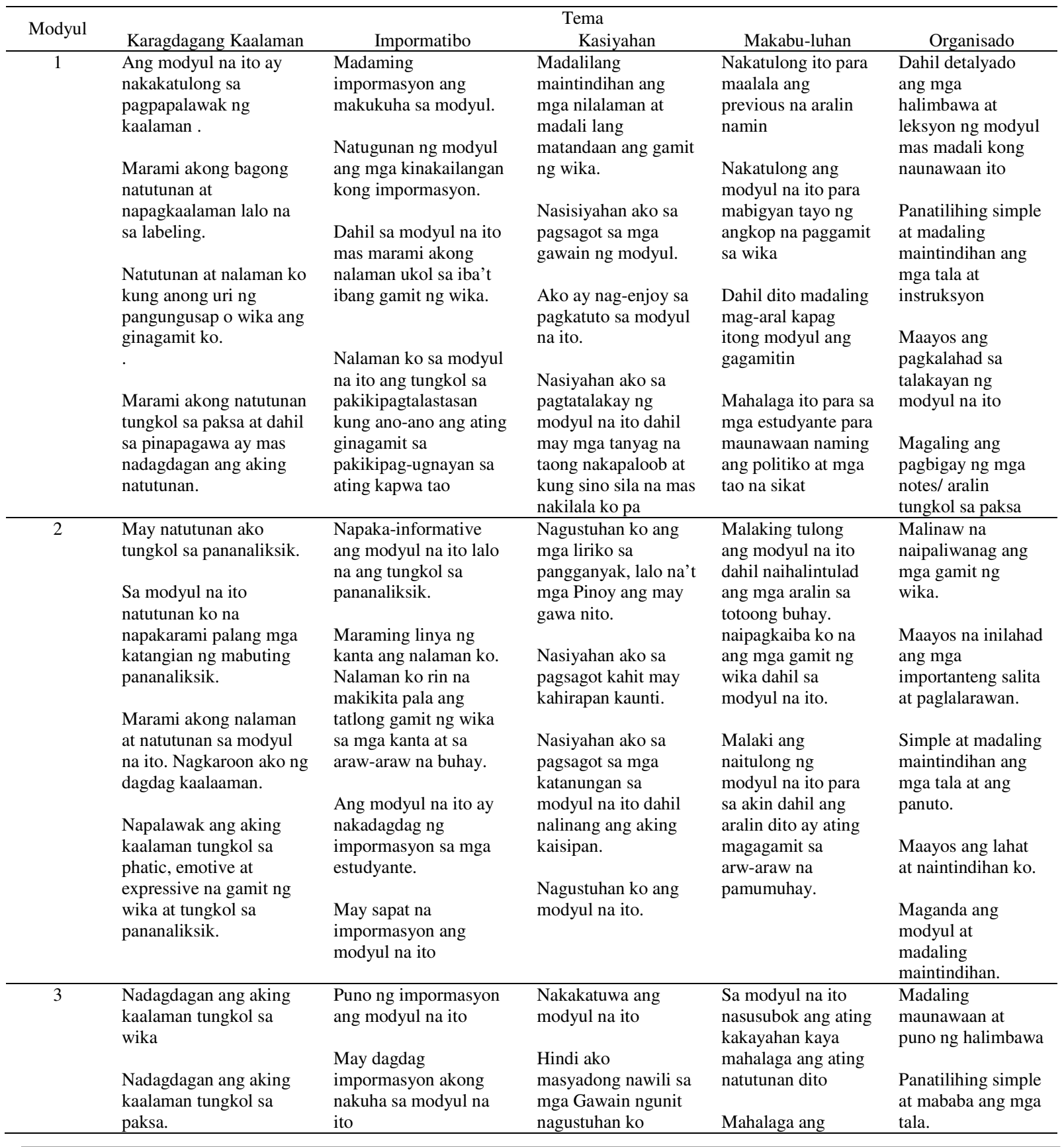




\begin{tabular}{|c|c|c|c|c|c|}
\hline & $\begin{array}{l}\text { Sa modyul na ito mas } \\
\text { napalawak pa ang aking } \\
\text { kaalaman ukol sa gamit } \\
\text { ng wika. } \\
\text { Medyo nahirapan ako sa } \\
\text { pagsagot sa modyul na } \\
\text { ito pero natuto naman } \\
\text { ako }\end{array}$ & $\begin{array}{l}\text { Maimpormasyon ang } \\
\text { modyul na ito. } \\
\text { May sapat na } \\
\text { impormasyon ang } \\
\text { ibinigay ng modyul } 3 \\
\text { kaya mas madali siyang } \\
\text { maintindihan ang } \\
\text { paggamit ng wika. } \\
\text { Maraming nakasaad na } \\
\text { mga impormasyong } \\
\text { nakatulong upang } \\
\text { maunawaan ko ang } \\
\text { paksa }\end{array}$ & $\begin{array}{l}\text { naman ang paggawa } \\
\text { ng slogan. Na-enjoy } \\
\text { ko ito nang sobra. } \\
\text { Nasiyahan ako dahil } \\
\text { maraming } \\
\text { halimbawa na } \\
\text { madaling } \\
\text { maunawaan. } \\
\text { Nagustuhan ko ang } \\
\text { mga Gawain sa } \\
\text { modyul na ito }\end{array}$ & $\begin{array}{l}\text { modyul para sa mga } \\
\text { estudyante. } \\
\text { Mahalaga ang aralin } \\
\text { sa modyul na ito } \\
\text { para sa mga } \\
\text { estudyante dahil sa } \\
\text { kalaunan ay } \\
\text { mag-research na } \\
\text { kami }\end{array}$ & $\begin{array}{l}\text { Maayos ang } \\
\text { pagkasunud-sunod } \\
\text { ng imporma-syon. } \\
\text { Maayos ang } \\
\text { pagkalahad ng } \\
\text { modyul na ito. } \\
\text { Nandito lahat ng } \\
\text { mga sagot sa } \\
\text { tanong. } \\
\text { Ang modyul } 3 \text { ay } \\
\text { Mas organisado } \\
\text { ang pagpresenta ng } \\
\text { mga imporma-syon }\end{array}$ \\
\hline \multirow[t]{2}{*}{4} & $\begin{array}{l}\text { Marami akong natutunan } \\
\text { at nalaman sa modyul na } \\
\text { ito. } \\
\text { Natutunan ko ang } \\
\text { tungkol sa plagyarismo. }\end{array}$ & $\begin{array}{l}\text { Maraming } \\
\text { impormasyon ang } \\
\text { napaloob kaya mas } \\
\text { nakaintindi ang } \\
\text { mag-aaral. }\end{array}$ & $\begin{array}{l}\text { Naganyak akong } \\
\text { sumagot sa mga } \\
\text { exercises na } \\
\text { nakalagay sa } \\
\text { modyul. }\end{array}$ & $\begin{array}{l}\text { Nakakatulong sa } \\
\text { aking pagkatao ang } \\
\text { mga kaalamang } \\
\text { natutunan ko sa } \\
\text { modyul na ito. }\end{array}$ & $\begin{array}{l}\text { Maayos na inilahad } \\
\text { ang paksa. } \\
\text { Simple at madaling } \\
\text { maintindihan ang } \\
\text { paglalahad. }\end{array}$ \\
\hline & $\begin{array}{l}\text { Naintindihan kong lalo } \\
\text { ang pagkakaiba sa } \\
\text { interaksyunal, } \\
\text { imahinatibo at personal } \\
\text { na gamit ng wika }\end{array}$ & $\begin{array}{l}\text { May sapat na } \\
\text { impormasyon ang } \\
\text { modyul } 4 \text { pero } \\
\text { nakulangan ako sa mga } \\
\text { halimbawa ng } \\
\text { interaksyunal, personal } \\
\text { at imahinatibong } \\
\text { tungkulin ng wika. }\end{array}$ & $\begin{array}{l}\text { Ayos lang! } \\
\text { Nakakaaliw } \\
\text { Nalilibang ako sa } \\
\text { pagsagot sa Gawain } \\
\text { tungkol sa } \\
\text { imahinatibong } \\
\text { yungkulin ng wika. }\end{array}$ & $\begin{array}{l}\text { Makabuluhan ang } \\
\text { mga pagsasanay na } \\
\text { maiaplay sa totoong } \\
\text { buhay. } \\
\text { Sa modyul na ito } \\
\text { natulungan akong } \\
\text { makaintindi ng mas } \\
\text { mabuti }\end{array}$ & $\begin{array}{l}\text { Maayos na } \\
\text { pagkaayos ang } \\
\text { lahat sa modyul. } \\
\text { Maayos ang } \\
\text { pagkalahad at } \\
\text { madali lang itong } \\
\text { pag-aralan }\end{array}$ \\
\hline
\end{tabular}

Gamit ang metodong "thematic analysis approach", nasuri ng mananaliksik ang patern ng mga nakasulat na pidbak ng mga estudyante. Batay sa pag-aanalisa ng mananaliksik ito ay nagbubunyag ng limang pangunahing tema na lumilitaw mula sa mga komento/ pidbak gamit ang likhang-modyul. Ang mga temang ito ay ang 1) Karagdagang Kaalaman; 2) Impormatibo; 3) Kasiyahan; 4) Makabuluhan; at 5) Organisado.

Ang limang pangunahing tema ay pinapangalanan gamit ang tuwirang sipi o pahayag mula sa pidbak ng mga estudyante. Makikita sa talahanayan na nangingibabaw ang temang karagdagang kaalaman. Karaniwan sa mga respondente ang tuwirang nagpahayag na marami silang natututunan sa nilalaman ng modyul at nadagdagan ang kanilang kaalaman tungkol sa paksa. Sa temang impormatibo, ang mga estudyante ay nagpapahayag na maraming impormasyon ang nakukuha sa modyul na kung saan natutugunan ang kanilang gustong matutunan. May sapat na impormasyon tungkol sa paksa na nagdaragdag sa kanilang kaalaman. Ilan sa mga estudyante ay nagpapahayag ng kanilang kasiyahan sa likhang-modyul. Karaniwan ay nagpapahayag na nagustuhan nila ang mga gawain o pagsasanay na ibinigay sa bawat paksa, kaya, natutuwa at naaliw sila sa pagsagot dahil nahamon ang kanilang kakayahan. Makabuluhan din ang likhang-modyul para sa mga estudyante dahil para sa kanila ang mga nilalaman ng modyul lalo na sa saklaw ng paksa ay nagbibigay ng magandang aral sa kanila na magamit sa araw-araw na pamumuhay bilang estudyante o isang mamamayan. Sa temang organisado, pinahayag ng mga estudyante na maayos ang pagkalahad sa mga bahagi ng modyul. Ang paksa o aralin ay detalyadong naitalakay kaya't madali itong maintindihan.

Sa naging resulta ng pidbak ng mga estudyante, naipakita ng likhang-modyul ang kalinawan, kawastuan, kaangkupan at kawilihan sa nilalaman at kasanayang dapat matututunan ng mga estudyante. Napansin din ang mga kinakailangan ng modyul para sa kahusayan nito tungo sa pagpapayaman ng likhang-modyul.

\section{Kongklusyon at rekomendasyon}

Ang pag-aaral ay isinagawa sa layuning mataya ang kahusayan at kabisaan ng likhang-modyul. Sa pagtatayang ginawa sa kaangkupang pangnilalaman ng likhang-modyul ay nangangahulugan na ang kaangkupang pangnilalaman nito ay angkop na angkop. Sa pagsusuri sa kabisaan nito ay napag-alaman na mabisang-mabisa ang mga bahagi tulad ng paksa, talakayan, malikhaing gawain at ebalwasyon. Batay sa pidbak ng mga estudyante, ay naipakita sa likhang-modyul ang kalinawan, kawastuan, kaangkupan at kawilihan sa 
nilalaman at kasanayang dapat matutunan ng mga estudyante at kinakailangan ang modyul para sa kahusayan nito tungo sa pagpapayaman ng likhang-modyul.

Sa pagsasaalang-alang sa mga impormasyon at sa mga datos ng isinagawang pag-aaral tungkol sa kahusayan at kabisaan ng likhang-modyul, nagpapatunay na ang kalayaan sa paggawa ng modyul ay higit na epektibo at nagdudulot ng kasiyahan sa pagpapahalaga at pagkatuto. Iminumungkahi na dagdagan pa ng mga halimbawa ang talakayan para lubusang maunawaan at maintindihan. Ninanais din na sana lagyan ng mga larawan o emoji at kulayan ang mga bahagi ng modyul para sa ikatuto ng mga estudyanteng "Visual Learners" at lalong mahahalina sa pagbasa ang mga estudyante.

Inirekomenda rin sa pag-aaral na ito na kailangan mataya ang kagamitang panturo o modyul batay sa kaangkupang pangnilalaman para sa kahusayan at kabisaan nito; pagandahin ang paglalahad ng modyul bilang kagamitang panturo gamit ang mga gawaing inobatibo at gawaing sitwasyong pangkomunikatibo para sa kabisaan nito; maglagay ng mga makukulay na larawan at biswal sa mga komunikatibong kagamitan o modyul upang lalong kaakit-akit at kawili-wili ang pag-aaral sa linggwistika at pananaliksik; at ipagpatuloy ang pagtataya sa kabisaan ng modyul upang malawakang magamit sa pagtuturo;

\section{Sanggunian}

Carpio-Bernido, M. (2012). The K to 12 curriculum (Mini Critique). The Philippine Star.

Kitao, K. (1997). Selecting and developing teaching/learning materials. The Internet TESL Journal, 4(4).

Liwanag, L. B. (2012). Ang Filipino sa K-12 batayang kurikulum sa edukasyon. Philippine Normal University. Luistro, A. (2012). Pambungad na pananalita sa paglunsad ng K to 12 basic education program. Rizal Ceremonal Hall, Palasyo ng Malakanyang.

Richards J. C., \& Rodgers T. S. (2001). Approaches and methods in language teaching. Cambridge University Press. New York USA. https://doi.org/10.1017/CBO9780511667305

Tomlinson, B. (1998). Developing materials for language teaching. Cambridge University Press. New York USA.

Zamora, N. C. L. (2016). Development and validation of a web-based module to teach metacognitive learning strategies to student in higher education (Unpublished Dissertation). University of South Florida. USA. 
Oclinaria, A. 